\title{
Sexual risk behaviors, HIV, and syphilis among female sex workers in Nepal
}

\section{Sampurna Kakchapati' Dipendra Raman Singh ${ }^{2}$ Bir Bahadhur Rawal ${ }^{2}$ Apiradee Lim'}

'Department of Mathematics and Computer Science, Prince of Songkla University, Pattani, Thailand; ${ }^{2}$ National Centre for AIDS and STD Control, Kathmandu, Nepal
Correspondence: Apiradee Lim Department of Mathematics and Computer Science, Prince of Songkla University, Rusamalie-4, Pattani 94000 ,

Thailand

Tel +6673313950

Fax +6673372179

Email apiradee.s@psu.ac.th
This article was published in the following Dove Press journal:

HIVIAIDS - Research and Palliative Care

27 January 2017

Number of times this article has been viewed

Purpose: Female sex workers (FSWs) are a key-affected population susceptible to acquiring HIV and sexually transmitted infections (STIs), as well as transmitting the virus to others. The aim of the study was to assess HIV and syphilis prevalence among FSWs in Nepal and to examine factors associated with it.

Materials and methods: The study was based on Integrated Biological and Behavioral Surveillance (IBBS) surveys among FSWs in Nepal from 2004 to 2015. Statistical analysis used chi-squared test to assess statistically significant risk factors for HIV and syphilis. Logistic regression models were used to identify the most important determinants for each outcome.

Results: A total of 5,958 FSWs were tested, and among them, 100 (1.7\%) were HIV positive and $230(3.9 \%)$ were syphilis positive. The multivariate analysis revealed that syphilis was higher among those street-based, aged $\geq 35$ years, illiterate, and with a duration of sex work of $>3$ years. HIV was higher among those aged $\geq 35$ years, illiterate, street-based, and with a duration of sex work $>3$ years. Syphilis was strongly correlated with HIV.

Conclusion: HIV epidemic among FSWs in Nepal appears in the stagnant trend, whereas STI epidemic has increased in recent years. The high influencing factors for HIV and syphilis prevalence were advanced age, street-based, lower education, and longer duration of sex work. Urgent efforts, as part of routine HIV/STI prevention and intervention, are required to reduce the high burden of syphilis among FSWs.

Keywords: IBBS, sex workers, sexual behaviors, surveillance

\section{Introduction}

Sex work is defined as the exchange of sex for money. The kind and structure of sex work vary substantially around the world. Those who sell sex might work with or without a facilitator or controller (eg, pimp and manager) through establishments, such as bars, brothels, or saunas, or in more public spaces, such as parks and streets. ${ }^{1}$ It is widely accepted that female sex workers (FSWs) are a high-risk group susceptible to acquiring HIV and sexually transmitted infections (STIs), as well as transmitting the virus to others. ${ }^{2-5}$ As many FSWs work in public areas, such as on the streets and in bars, hotels, cabin restaurants, massage parlors, and brothels (also known as establishment-based FSWs), they are considered as mediators, who are a source of STIs and HIV infection to the general population, mainly as a result of unprotected sex with their clients. ${ }^{2,6}$

Nepal is categorized as a country facing concentrated HIV epidemic. The National Centre for acquired immune deficiency syndrome (AIDS) and sexually transmitted disease (STD) Control has estimated that there were 39,249 people living with HIV in Nepal in 2014 with adult HIV prevalence of $0.20 \%$. The National HIV and AIDS 
Strategy (2011-2016) identify FSWs as one of the keyaffected population at higher risk of $\mathrm{HIV}^{7} \mathrm{HIV}$ infection among FSWs in Nepal varies by the epidemic typology, ${ }^{3}$ structure of sex work (street and establishment), ${ }^{4}$ and overlapping nature of HIV risk behaviors, such as injection drug use. $^{7}$ The risk of HIV acquisition and transmission among FSWs comprises biological and behavioral risks. ${ }^{8}{ }^{8}$ Biological risk factors involve the high prevalence of bacterial STIs in FSWs ${ }^{10}$ and the synergistic relationship between HIV and STIs. ${ }^{11}$ Behavioral risk factors act at the level of the individual, with sex workers experiencing high sexual risks through high numbers of sexual partners and high concurrency of these partners. HIV transmission among sex workers is also exacerbated by the intersection of injection drug use, sex with more HIV-positive partners, low and inconsistent condom use, and increased risk of other STIs, such as syphilis and hepatitis C. ${ }^{12-14}$

FSWs in Nepal are increasing as many young girls get lured into selling sex due to migration from rural to urban cities in search of work. The number of FSWs in Nepal also varies with different geographical settings and more concentrated in the many urban areas, such as Kathmandu, Pokhara, and Terai highway border areas. ${ }^{3}$ Although studies have also documented that the HIV prevalence among Nepali FSWs is in a decreasing trend (2004-2015), these studies still report that unsafe sex practices between FSWs and their clients are not uncommon. For example, the most recent Integrated Biological and Behavioral Surveillance (IBBS) surveys among FSWs in Kathmandu, Pokhara, and Terai highway districts revealed that consistent condom use with clients over past 12 months was not satisfactory and the consistent condom use with nonpaying partners in Kathmandu and Pokhara was even lower. ${ }^{4,5,15}$ FSWs described high numbers of sexual encounters every day with different categories of male partners. The situation may get more complex in case of drug abuse and needle sharing FSWs who are more prone to be infected with HIV and other STIs more than nonusers.

Studies have delineated that the behavioral and sociodemographic factors were associated with HIV and STI infection among FSWs. Lifestyle variables, socioeconomic factors, and psychosocial propensity are elements that influence HIV preventive behaviors and lead to HIV and STI infection among FSWs. ${ }^{12-14}$ Although several studies have reported determinants of HIV globally, ${ }^{12-14}$ studies on the risk of HIV infection among FSWs in Nepal are limited. Therefore, there is a need to investigate the prevalence of HIV and syphilis and high-risk behaviors among FSWs. With this view and importance, this study used biological and behavioral surveillance data to provide an updated comprehensive assessment of the epidemic situation among FSW using 13 rounds of IBBS surveys. This study aims to assess the prevalence of HIV, syphilis, and social and behavioral correlates of HIV and STI infection among FSWs in Nepal.

\section{Materials and methods}

This study is based on retrospective analysis of IBBS surveys among FSW in Nepal from 2004 to 2016. IBBS surveys were cross-sectional in design and were conducted in Kathmandu valley, Pokhara valley, and 22 Terai highway districts of Nepal. FSWs were defined as "women aged $\geq 16$ years who reported being paid in cash or kind for sex with a male within the last 6 months."

Two-stage cluster sampling method was used to draw FSWs from the study sites in all rounds of IBBS surveys. Face-to-face interviews were conducted by trained field workers in the local language, Nepali, using a structured questionnaire that included questions on background characteristics (age, year, region, education, marital status, and type of sex work), sexual behaviors (duration of their involvement in the sex trade, average number of the clients, and total number of working days), and injecting behaviors (the use of drugs and injecting practices). The sex partners of the FSW were categorized as clients, regular clients, nonpaying partners, and other partners. Nonpaying partners included boyfriends, husbands, or those who do not pay for sexual services, whereas clients and regular partners included those partners who pay for sexual contact. Partners other than clients, husbands, and male friend(s) were categorized as other partners who include massage owners and police officials. In addition, biological samples were tested for HIV and syphilis.

IBBS surveys were conducted in compliance with both ethical and human rights standards. Ethical approval for this survey was obtained from Nepal Health Research Council. Verbal informed and witnessed consent was obtained from all the FSWs before the interview and collection of blood samples. Study centers with laboratories/clinics were set up at easily accessible locations in all the study districts. Individual interviews, clinical examinations, and blood collection were carried out in separate rooms in each of the study centers. Blood samples were collected from all the study participants and were tested for HIV and syphilis. HIV testing was done using Determine HIV 1/2 as the primary method for detecting antibodies against HIV. If the first test presented a negative result, then no further tests were conducted. However, if the first test was positive, a second test was performed using Uni-Gold. In case of a tie between the first two tests, a third 
test was performed using Stat Pak HIV 1/2 as a tie-breaker test. Syphilis was tested using the rapid plasma reagent test card and confirmed by means of the Serodia Treponema pallidum particle agglutination test. Serum samples that tested rapid plasma reagent positive with titer value $\geq 1: 8$ were reported as active syphilis; titration $<1: 8$ were reported as a case with a history of syphilis.

\section{Statistical analysis}

Bivariate analyses were conducted to estimate the association of demographic and behavioral variables with HIV and syphilis prevalence using chi-squared tests. Logistic regression analyses were performed to determine variables associated with HIV and syphilis proportion defined by the combinations of the determinants. First, the preliminary logistic multivariate model was carried out among determinants that were significant in the bivariate analyses. Then, a list of determinants that were significant in the preliminary multivariate model was obtained and fitted in the final multivariable logistic model. Sum contrasts were used to obtain confidence intervals for comparing each proportion with the overall proportion. As it is necessary to construct specific contrasts for logistic regression, this can be accomplished by using a weighted sum contrasts rather than treatment contrasts, ${ }^{16}$ where the first level is left out of the model to be the reference. ${ }^{17}$ The advantage of using appropriately weighted sum contrasts is that each proportion can be compared with the overall proportion rather than with a specified reference group. The computed $95 \%$ confidence intervals provide a way of classifying the levels of each factor into three groups according to whether each corresponding confidence interval exceeds, crosses, or is below the overall proportion. ${ }^{18}$ The confidence intervals compare the percent of HIV and syphilis in each category of a factor with the overall percent. To compare models for prevalence, we used the area under the receiver operating characteristic (ROC) curve as a measure of goodness-of-fit and constructed mosaic plot. ROC plots sensitivity against the false-positive rate to show how well a model predicts a binary outcome. For a range of decision choices, it plots sensitivity (probability of finding an outcome when it is there) against the false-positive error rate (probability of finding an outcome when it is not there). It also gives mosaic plot for comparing logistic regression models similar to $r^{2}$ decomposition plot. R program was used for statistical analysis and creating graphs.

\section{Results}

A total of 5,958 FSWs were included in the analysis from 2004 to 2015 , of whom $3.9 \%$ of FSWs (230) tested syphilis positive. Table 1 shows the association of background characteristics, sexual behaviors, and drug injecting practices with syphilis. Year, region, age, marital status, education, place of work, duration of sex work, number of clients per day, number of clients in past week, and consistent condom used

Table I Association between background characteristics, sexual behaviors, drug injecting behaviors, and syphilis among FSWs

\begin{tabular}{|c|c|c|c|c|c|}
\hline \multirow[t]{2}{*}{ Characteristics } & \multirow{2}{*}{$\begin{array}{l}\text { Total }(n=5958) \\
n(\%)\end{array}$} & \multirow{2}{*}{$\begin{array}{l}\text { Syphilis }(n=230,3.9 \%) \\
n(\%)\end{array}$} & \multirow{2}{*}{$\begin{array}{l}\text { Not syphilis }(\mathrm{n}=5728,96.1 \%) \\
\mathrm{n}(\%)\end{array}$} & \multirow[t]{2}{*}{$\chi_{(\mathrm{d})}^{2}$} & \multirow[t]{2}{*}{$p$-Value } \\
\hline & & & & & \\
\hline \multicolumn{6}{|l|}{ Year } \\
\hline 2004 & $700(11.7)$ & $62(8.9)$ & 638 (91.1) & $176(7)$ & $<0.001$ \\
\hline 2006 & $\mid 300(2 \mid .8)$ & $50(3.8)$ & $1250(96.2)$ & & \\
\hline 2008 & 700 (II.7) & $8(I . I)$ & $692(98.9)$ & & \\
\hline 2009 & $600(10.1)$ & $2 \mathrm{I}(3.5)$ & $579(96.5)$ & & \\
\hline 2011 & 938 (I5.7) & $6(0.6)$ & $932(99.4)$ & & \\
\hline 2012 & $610(10.2)$ & $2(0.3)$ & 608 (99.7) & & \\
\hline 2015 & $500(8.4)$ & $18(3.6)$ & $482(96.4)$ & & \\
\hline 2016 & $610(10.2)$ & $63(10.3)$ & 547 (89.7) & & \\
\hline \multicolumn{6}{|l|}{ Region } \\
\hline Kathmandu & $2593(43.5)$ & $96(3.7)$ & $2497(96.3)$ & $12.6(2)$ & 0.002 \\
\hline Pokhara & 945 (15.9) & $20(2.1)$ & 925 (97.9) & & \\
\hline Terai & $2420(40.6)$ & $114(4.7)$ & $2306(95.3)$ & & \\
\hline \multicolumn{6}{|l|}{ Place of work } \\
\hline Street & $1936(32.5)$ & $87(4.5)$ & 1849 (95.5) & $51.8(I)$ & $<0.001$ \\
\hline Establishment & $4022(67.5)$ & 143 (3.6) & 3879 (96.4) & & \\
\hline \multicolumn{6}{|l|}{ Age, years } \\
\hline$<20$ & $2094(35.1)$ & $72(3.4)$ & $2022(96.6)$ & $7.1(2)$ & 0.023 \\
\hline $21-29$ & $2342(39.3)$ & $82(3.5)$ & $2260(96.5)$ & & \\
\hline$\geq 30$ & $1522(25.5)$ & $76(5.0)$ & 1446 (95.0) & & \\
\hline
\end{tabular}


Table I (Continued)

\begin{tabular}{|c|c|c|c|c|c|}
\hline \multirow[t]{2}{*}{ Characteristics } & \multirow{2}{*}{$\begin{array}{l}\text { Total }(n=5958) \\
n(\%)\end{array}$} & \multirow{2}{*}{$\begin{array}{l}\text { Syphilis (n=230, 3.9\%) } \\
\mathrm{n}(\%)\end{array}$} & \multirow{2}{*}{$\begin{array}{l}\text { Not syphilis }(\mathrm{n}=5728,96.1 \%) \\
\mathrm{n}(\%)\end{array}$} & \multirow[t]{2}{*}{$\chi_{(\mathrm{df})}^{2}$} & \multirow[t]{2}{*}{$p$-Value } \\
\hline & & & & & \\
\hline \multicolumn{6}{|l|}{ Education } \\
\hline No education & $2064(34.6)$ & $134(6.5)$ & $1930(93.5)$ & $61.2(2)$ & $<0.001$ \\
\hline Primary & $2146(36.1)$ & $62(2.9)$ & $2084(97.1)$ & & \\
\hline Secondary and above & $1748(29.3)$ & $34(1.9)$ & $1714(98.1)$ & & \\
\hline \multicolumn{6}{|l|}{ Marital status } \\
\hline Single & $1567(26.3)$ & $27(1.7)$ & $1540(98.3)$ & $30(2)$ & $<0.001$ \\
\hline Married & $2799(47.0)$ & $116(4.1)$ & $2683(95.9)$ & & \\
\hline Separated (widow/divorced) & $1592(26.7)$ & $87(5.5)$ & I505 (94.5) & & \\
\hline \multicolumn{6}{|l|}{ Duration of sex work, years } \\
\hline$<1$ & $2203(37.0)$ & $38(1.7)$ & $2165(98.3)$ & $5 \mathrm{I.I}(2)$ & $<0.001$ \\
\hline $1-3$ & $2240(37.6)$ & $98(4.4)$ & $2142(95.6)$ & & \\
\hline$>3$ & $1515(25.4)$ & $94(6.2)$ & |42| (93.8) & & \\
\hline \multicolumn{6}{|l|}{ Age of first sexual contact, years } \\
\hline$<20$ & $5647(94.8)$ & $215(3.8)$ & $5432(96.2)$ & $0.57(\mathrm{I})$ & 0.452 \\
\hline$\geq 20$ & $311(5.2)$ & $15(4.8)$ & $296(95.2)$ & & \\
\hline \multicolumn{6}{|l|}{ Total number of sexual partners } \\
\hline I & $573(9.6)$ & $26(4.5)$ & $547(95.5)$ & $0.59(1)$ & 0.443 \\
\hline$>1$ & $5385(90.4)$ & $204(3.8)$ & $5181(96.2)$ & & \\
\hline \multicolumn{6}{|l|}{ Number of clients per day } \\
\hline $\mathrm{I}$ & $415(7.0)$ & $36(8.7)$ & $379(91.3)$ & $26(I)$ & $<0.001$ \\
\hline$>1$ & $5543(93.0)$ & $194(3.5)$ & $5349(96.5)$ & & \\
\hline \multicolumn{6}{|l|}{ Number of clients in past week } \\
\hline I & $816(13.7)$ & $43(5.3)$ & $773(94.7)$ & $4.6(1)$ & 0.033 \\
\hline$>1$ & $5142(86.3)$ & $187(3.6)$ & $4955(96.4)$ & & \\
\hline \multicolumn{6}{|l|}{ Number of clients in past year } \\
\hline I & $3339(56.0)$ & $134(4.0)$ & $3205(96.0)$ & $0.39(1)$ & 0.537 \\
\hline$>1$ & $2619(44.0)$ & $96(3.7)$ & $2523(96.3)$ & & \\
\hline \multicolumn{6}{|c|}{ Number of working days in a week } \\
\hline$\leq 2$ & $513(8.6)$ & $20(3.9)$ & $493(96.1)$ & $0.2(\mathrm{I})$ & 0.922 \\
\hline$>2$ & $5445(91.4)$ & $210(3.9)$ & $5235(96.1)$ & & \\
\hline \multicolumn{6}{|c|}{ Consistent condom used with clients } \\
\hline Yes & $5127(86.1)$ & $180(3.5)$ & $4947(96.5)$ & $1 \mathrm{I} .4(\mathrm{I})$ & $<0.001$ \\
\hline No & $831(13.9)$ & $50(6.0)$ & $78 I(94.0)$ & & \\
\hline \multicolumn{6}{|c|}{ Consistent condom use with regular partners } \\
\hline Yes & $3755(63)$ & $124(3.3)$ & $3631(96.7)$ & $8.1(1)$ & 0.004 \\
\hline No & $2203(37)$ & $106(4.8)$ & $2097(95.2)$ & & \\
\hline \multicolumn{6}{|c|}{ Consistent condom use with nonpaying partners } \\
\hline Yes & $1217(20.4)$ & $43(3.5)$ & $1174(96.5)$ & $0.34(1)$ & 0.563 \\
\hline No & $474 \mid(79.6)$ & $187(3.9)$ & $4554(96.1)$ & & \\
\hline \multicolumn{6}{|l|}{ Ever used drug } \\
\hline Yes & $369(6.2)$ & $14(3.8)$ & $355(96.2)$ & $0.1(1)$ & 0.921 \\
\hline No & $5589(93.8)$ & $216(3.9)$ & $5373(96.1)$ & & \\
\hline \multicolumn{6}{|l|}{ Ever injected drug } \\
\hline Yes & $94(1.6)$ & $4(4.3)$ & $90(95.7)$ & $0.3(\mathrm{I})$ & 0.917 \\
\hline No & 5864 (98.4) & 226 (3.9) & $5638(96.1)$ & & \\
\hline
\end{tabular}

Abbreviation: df, degrees of freedom; FSWs, female sex workers.

with clients and regular partners were found to be statistically significant with syphilis ( $p$-value $<0.05$ ).

Region, place of work, age, education, marital status, duration of sex work, number of clients in past week, ever injected drugs, and presence of syphilis were significantly associated with HIV prevalence, as shown in Table 2 ( $p$-value $<0.05)$.
All determinants significant in bivariate analysis were included in the preliminary multivariate model. In multivariate logistic regression, year, region, age, education, type of sex work, and duration of sex work were significantly associated with syphilis prevalence. However, the study found the interaction between year and region, age and education, and type of sex work and duration of sex work. Hence, year 
Table 2 Association between background characteristics, sexual behaviors, drug injecting behaviors, and HIV among FSWs

\begin{tabular}{|c|c|c|c|c|c|}
\hline \multirow[t]{2}{*}{ Characteristics } & \multirow{2}{*}{$\begin{array}{l}\text { Total }(n=5958) \\
n(\%)\end{array}$} & \multirow{2}{*}{$\begin{array}{l}\text { HIV (n=100, I.7\%) } \\
\text { n (\%) }\end{array}$} & \multirow{2}{*}{$\begin{array}{l}\text { Not HIV (n=5858, 98.3\%) } \\
\text { n (\%) }\end{array}$} & \multirow[t]{2}{*}{$\chi_{(\mathrm{df})}^{2}$} & \multirow[t]{2}{*}{$p$-Value } \\
\hline & & & & & \\
\hline \multicolumn{6}{|l|}{ Year } \\
\hline 2004 & $700(11.7)$ & $14(2)$ & $686(98)$ & $9.5(7)$ & 0.212 \\
\hline 2006 & $1300(21.8)$ & $20(1.5)$ & $1280(98.5)$ & & \\
\hline 2008 & $700(11.7)$ & $17(2.4)$ & $683(97.6)$ & & \\
\hline 2009 & $600(10.1)$ & $14(2.3)$ & $586(97.7)$ & & \\
\hline 2011 & $938(15.7)$ & $14(1.5)$ & $924(98.5)$ & & \\
\hline 2012 & $610(10.2)$ & $6(1)$ & $604(99)$ & & \\
\hline 2015 & $500(8.4)$ & $10(2)$ & $490(98)$ & & \\
\hline 2016 & $610(10.2)$ & $5(0.8)$ & $605(99.2)$ & & \\
\hline \multicolumn{6}{|l|}{ Region } \\
\hline Kathmandu & $2593(43.5)$ & $48(1.9)$ & $2545(98.1)$ & $1.8(2)$ & 0.031 \\
\hline Pokhara & $945(15.9)$ & $18(1.9)$ & $927(98.1)$ & & \\
\hline Terai & $2420(40.6)$ & $34(1.4)$ & $2386(98.6)$ & & \\
\hline \multicolumn{6}{|l|}{ Place of work } \\
\hline Street & $1936(32.5)$ & $52(2.7)$ & I 884 (97.3) & $5.3(1)$ & 0.023 \\
\hline Establishment & $4022(67.5)$ & $48(1.2)$ & $3974(98.8)$ & & \\
\hline \multicolumn{6}{|l|}{ Age, years } \\
\hline$<20$ & $2094(35.1)$ & $20(I)$ & 2074 (99) & $7.1(2)$ & 0.026 \\
\hline $21-29$ & $2342(39.3)$ & $42(1.8)$ & $2300(98.2)$ & & \\
\hline$\geq 30$ & $1522(25.5)$ & $38(2.5)$ & 1484 (97.5) & & \\
\hline \multicolumn{6}{|l|}{ Education } \\
\hline No education & $2064(34.6)$ & $57(2.8)$ & 2007 (97.2) & $22.5(2)$ & $<0.001$ \\
\hline Primary & $2146(36)$ & $25(1.2)$ & $2121(98.8)$ & & \\
\hline Secondary and above & $1748(29.3)$ & $18(1)$ & $1730(99)$ & & \\
\hline \multicolumn{6}{|l|}{ Marital status } \\
\hline Single & $1567(26.3)$ & II (0.7) & 1556 (99.3) & $19.1(2)$ & $<0.001$ \\
\hline Married & $2799(47.0)$ & $46(1.6)$ & $2753(98.4)$ & & \\
\hline Separated (widow/divorced) & $1592(26.7)$ & $43(2.7)$ & $1549(97.3)$ & & \\
\hline \multicolumn{6}{|l|}{ Duration of sex work, years } \\
\hline$<1$ & $2203(37.0)$ & $28(I .3)$ & 2175 (98.7) & $\mid \mathrm{I} .5(2)$ & 0.032 \\
\hline $1-3$ & $2240(37.6)$ & $32(1.4)$ & $2208(98.6)$ & & \\
\hline$>3$ & $1515(25.4)$ & $40(2.6)$ & 1475 (97.4) & & \\
\hline \multicolumn{6}{|l|}{ Age of first sexual contact } \\
\hline$<20$ & $5647(94.8)$ & $98(1.7)$ & $5549(98.3)$ & $1.5(1)$ & 0.215 \\
\hline$\geq 20$ & $3 I I(5.2)$ & $2(0.6)$ & $309(99.4)$ & & \\
\hline \multicolumn{6}{|l|}{ Total number of sexual partners } \\
\hline 1 & $573(9.6)$ & $4(0.7)$ & $569(99.3)$ & $3 . I(I)$ & 0.085 \\
\hline$>1$ & $5385(90.4)$ & $96(1.8)$ & $5289(98.2)$ & & \\
\hline \multicolumn{6}{|l|}{ Number of clients per day } \\
\hline 1 & $415(7.0)$ & $2(0.5)$ & $413(99.5)$ & $3.1(1)$ & 0.073 \\
\hline$>1$ & $5543(93.0)$ & $98(1.8)$ & $5445(98.2)$ & & \\
\hline \multicolumn{6}{|l|}{ Number of clients in past week } \\
\hline 1 & $816(13.7)$ & $5(0.6)$ & $811(99.4)$ & $5.8(1)$ & 0.015 \\
\hline$>1$ & $5142(86.3)$ & $95(1.8)$ & $5047(98.2)$ & & \\
\hline Number of clients in past year & & & & & \\
\hline 1 & $3339(56.0)$ & $47(1.4)$ & $3292(98.6)$ & $3.1(1)$ & 0.082 \\
\hline$>1$ & $2619(44.0)$ & $53(2)$ & $2566(98)$ & & \\
\hline Number of working days in a $\mathrm{n}$ & & & & & \\
\hline$\leq 2$ & $513(8.6)$ & $3(0.6)$ & $510(99.4)$ & $3.4(1)$ & 0.063 \\
\hline$>2$ & $5445(91.4)$ & $97(1.8)$ & $5348(98.2)$ & & \\
\hline Consistent condom use with $\mathrm{cl}$ & & & & & \\
\hline Yes & $5127(86.1)$ & $90(1.8)$ & $5037(98.2)$ & I.I (I) & 0.367 \\
\hline No & $831(13.9)$ & $10(1.2)$ & $821(98.8)$ & & \\
\hline Consistent condom use with re & $r$ partners & & & & \\
\hline Yes & $3755(63.0)$ & $61(1.6)$ & $3694(98.4)$ & $0.1(I)$ & 0.723 \\
\hline No & $2203(37.0)$ & $39(1.8)$ & $2164(98.2)$ & & \\
\hline
\end{tabular}


Table 2 (Continued)

\begin{tabular}{|c|c|c|c|c|c|}
\hline \multirow[t]{2}{*}{$\overline{\text { Characteristics }}$} & \multirow{2}{*}{$\begin{array}{l}\text { Total }(n=5958) \\
n(\%)\end{array}$} & \multirow{2}{*}{$\begin{array}{l}\text { HIV (n=100, I.7\%) } \\
\text { n (\%) }\end{array}$} & \multirow{2}{*}{$\begin{array}{l}\text { Not HIV }(n=5858,98.3 \%) \\
n(\%)\end{array}$} & \multirow[t]{2}{*}{$\chi_{(\mathrm{d})}^{2}$} & \multirow[t]{2}{*}{$p$-Value } \\
\hline & & & & & \\
\hline \multicolumn{6}{|c|}{ Consistent condom used with nonpaying partners } \\
\hline Yes & $1217(20.4)$ & $22(1.8)$ & II 95 (98.2) & $0.1(I)$ & 0.856 \\
\hline No & $474 \mid(79.6)$ & 78 (1.6) & $4663(98.4)$ & & \\
\hline \multicolumn{6}{|l|}{ Ever used drug } \\
\hline Yes & $369(6.2)$ & $7(1.9)$ & $362(98.1)$ & $0.1(I)$ & 0.932 \\
\hline No & $5589(93.8)$ & $93(1.7)$ & $5496(98.3)$ & & \\
\hline \multicolumn{6}{|l|}{ Ever injected drug } \\
\hline Yes & $94(1.6)$ & $8(8.5)$ & $86(91.5)$ & $22.9(1)$ & $<0.001$ \\
\hline No & $5864(98.4)$ & $92(1.6)$ & $5772(98.4)$ & & \\
\hline \multicolumn{6}{|l|}{ Presence of syphilis } \\
\hline Yes & $230(3.9)$ & $13(5.7)$ & $217(94.3)$ & $20(I)$ & $<0.001$ \\
\hline No & $5728(96.1)$ & $87(1.5)$ & $564 \mid(98.5)$ & & \\
\hline
\end{tabular}

Abbreviations: $\mathrm{df}$, degrees of freedom; FSWs, female sex workers.

and region were combined. The number of levels of the year-region group factor depends on the year and region and there were 13 levels. Age and education were combined. The number of levels in the age group-education factor depends on the age and education distribution of HIV. For syphilis, we chose seven levels of age group-education factor with the education level and three age groups $(<20,21-30$, and $>30$ years). FSWs who had no education were merged into one group due to small sample size. Type of FSWs and duration of sex work were combined. The number of levels in the type-duration factor depends on the type (street and establishment) and duration $(<1,1-3$, and $>3$ years) distribution. In the logistic regression, year-region factor, age group-education factor, and type-duration factors were significantly associated with syphilis. The graph (Figure 1) shows results from fitting logistic model for syphilis prevalence, with year-region factor, age group-education factor, and type-duration factor as determinants. The model also highlights a substantial decrease in syphilis prevalence from 2004 to 2012 followed by an increase in 2015 and 2016 . Terai region had the highest prevalence of syphilis compared to other regions of Nepal. HIV prevalence increases with age. The prevalence was highest for those aged $\geq 30$ years. Education was significantly associated with syphilis as the highest prevalence was observed among FSW with no education in all age groups. Moreover, the prevalence

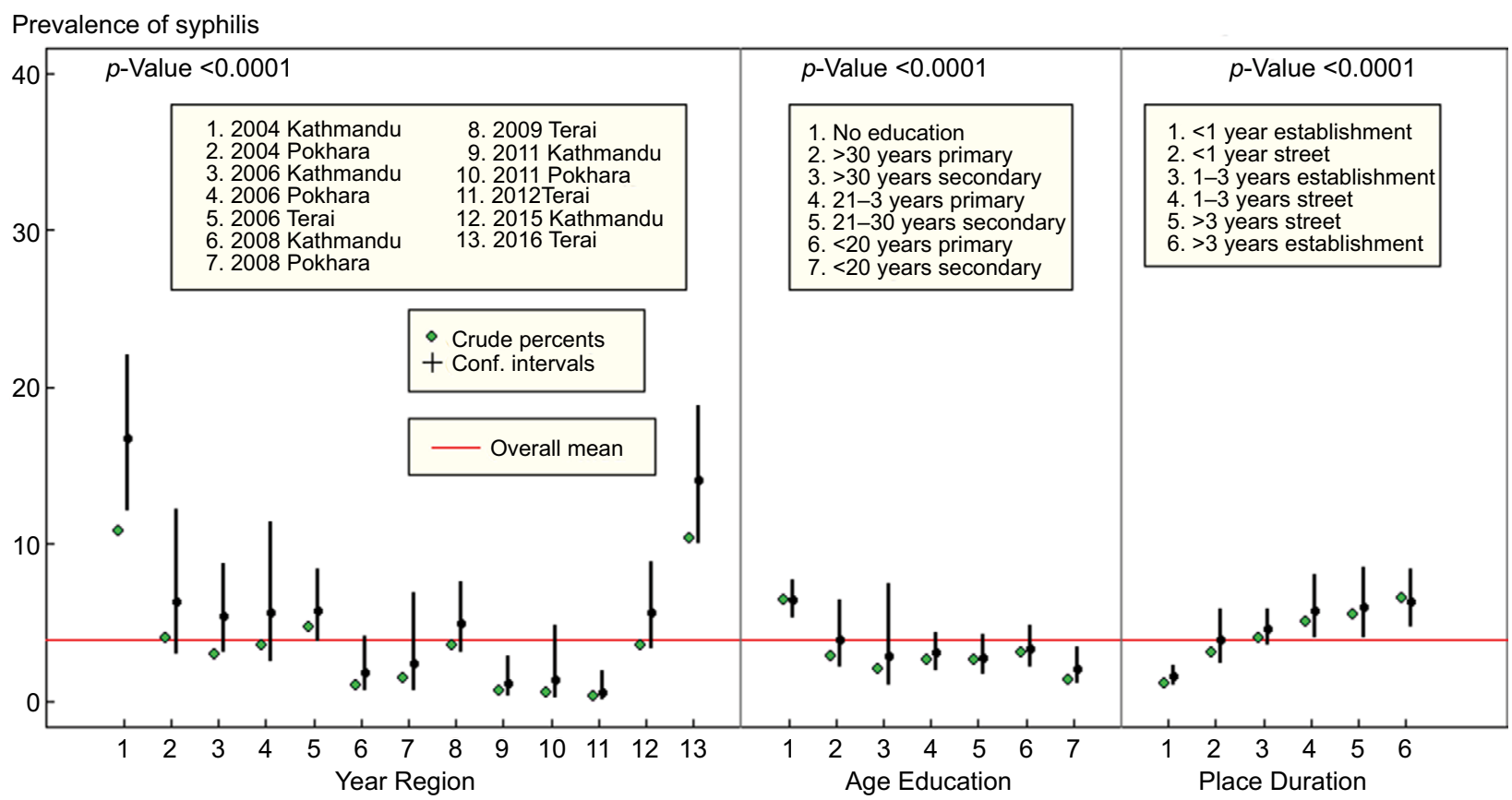

Figure I Factors associated with syphilis prevalence in multivariate logistic regression.

Abbreviations: Age Education, age-education factor; Place Duration, place of work-duration factor; Year Region, year-region factor. 


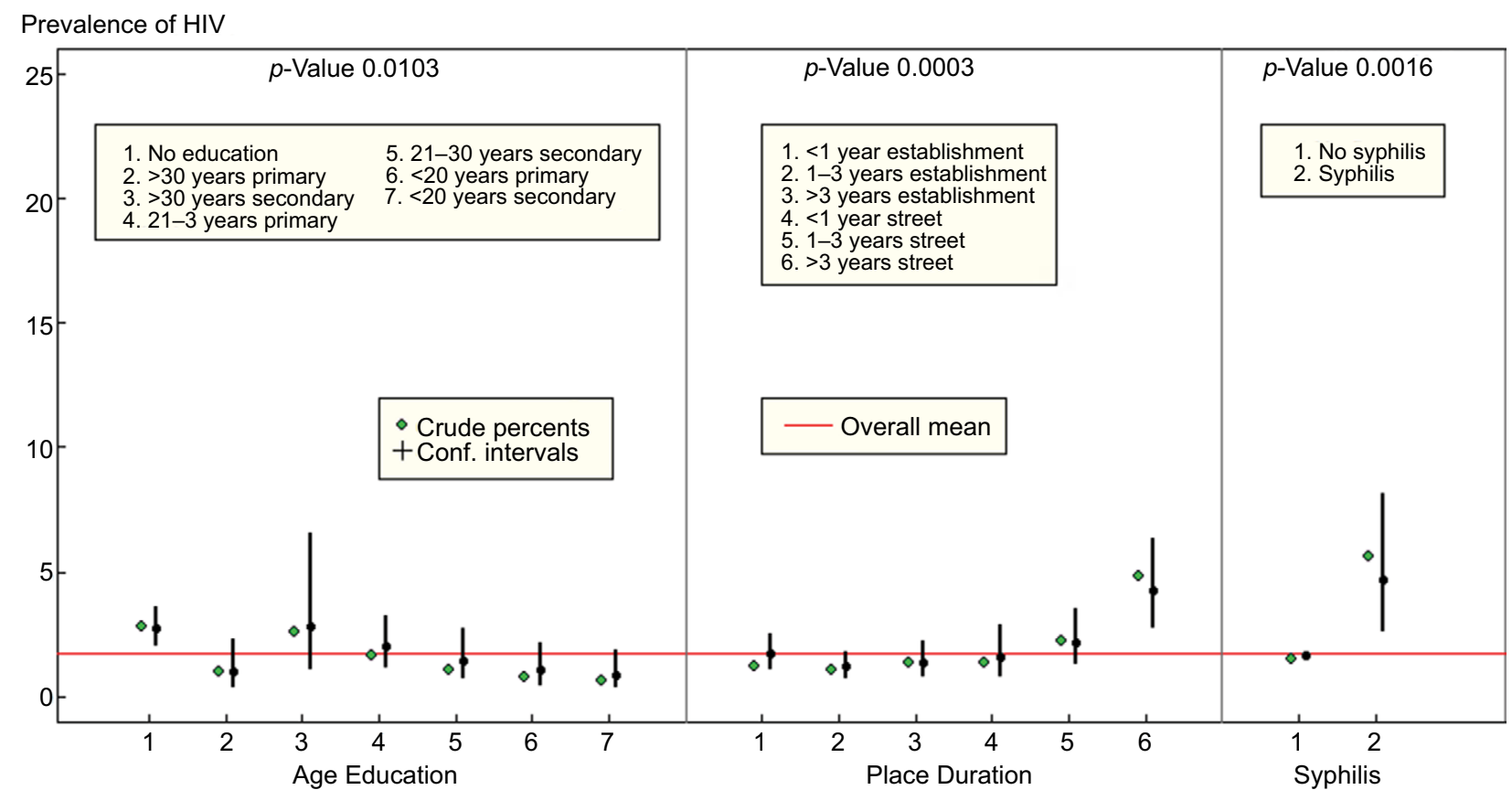

Figure 2 Factors associated with HIV prevalence in multivariate logistic regression. Abbreviations: Age Education, age-education factor; Place Duration, place of work-duration factor.

was higher among street-based FSWs and longer duration of sex work ( $>3$ years).

ROC curve for final model was fitted to syphilis prevalence. ROC curve shows that model containing year-region factor, age-education factor, and type-duration fits the prevalence data well.

In bivariate analysis, region, age, education, marital status, type of FSWs, duration of sex work, number of clients in the last week, ever injected drugs, and presence of syphilis were found to be statistically significant with HIV prevalence and were included in the preliminary multivariate model. Age, education, type of sex work, duration of sex work, and presence of syphilis were significantly associated with HIV prevalence in multivariate logistic regression. There were interaction between age and education and type of sex work and duration of sex work. Age and education were combined and type of FSWs and duration of sex work were combined. Figure 2 shows results from fitting logistic model for HIV prevalence, with age group-education factor, type-duration, and presence of syphilis as determinants. HIV prevalence was higher among FSW with no education in all age groups. Street-based FSWs with longer duration of sex work ( $>3$ years) had the highest HIV prevalence. HIV prevalence was higher among FSWs with presence of syphilis.

ROC curve for final model was fitted to HIV prevalence. The model containing age-education factor, type-duration, and presence of syphilis fits the HIV prevalence well.

\section{Discussion}

FSW continue to bear a substantial burden of HIV and STI infection in Nepal. IBBS survey analyses were undertaken to confirm that FSWs in Nepal are indeed at elevated risk for HIV and STI infection. The available evidence suggests that the HIV/AIDS epidemic among FSW in Nepal remain stagnant from 2004 to 2016, suggesting the need to reduce the prevalence of HIV among FSWs. In case of syphilis, the prevalence had dropped from 2002 to 2012 with significant increases in 2015 and 2016. The recent increase in syphilis had become a major concern and needs to be investigated by further research.

The prevalence of HIV and syphilis varied in three regions of Nepal. High HIV prevalence was found in Kathmandu valley and Pokhara valley compared with Terai highway districts. In Nepal, many young girls get lured into sex work to urban cities, such as Kathmandu and Pokhara, in quest of work. In the urban cities, they are exposed to a large number of clients and have a higher number of working days and possess high-risk sexual behaviors. ${ }^{4,5}$ Because of limited education, poor socioeconomic status, new to profession, young age, and poor knowledge of HIV/AIDS, these groups of FSWs are extremely vulnerable to HIV risk. ${ }^{19,20}$ Syphilis was found to be highest in Terai highway districts. Studies showed that FSWs in highway districts and border areas may have a higher risk of STI compared with their counterparts in both original and hosting countries as they are highly mobile and 
lack access to HIV/STI intervention. ${ }^{15,21,22}$ FSWs in highway districts are often from the lower castes, street-based and are often poor, uneducated, old age, came from rural areas and have a longer duration of sex work, and often deserted by their husbands or widowed.

Older age remained as strong predictors of HIV and syphilis infection, and these results corroborate the results of other FSW studies showing the increase of the HIV prevalence as age increases. ${ }^{23-25}$ Study identified that older age was an independent risk of unprotected sex, injection drug use, and a self-reported history of syphilis infection. ${ }^{25}$ Older FSWs are considered as disadvantaged groups compared to their younger FSWs in the competitive sex world. They are likely to go on the street, accept clients who are at a high risk of HIV infection or transmission or be willing to have unprotected sex for more money. ${ }^{26-28}$ Moreover, adolescent FSWs received more reinforcement from their managers to engage in safer sex compared to the older age groups..$^{29,30}$ A study found that lower HIV prevalence associated with women with a shorter period of professional practice who charged higher amounts for their services made frequent use of condoms. ${ }^{23}$ However, in cases of sexual risk exposures, studies show a greater occurrence of high-risk sexual behaviors among younger FSWs compared with older FSWs. Adolescent FSWs had a greater number of sex clients per week and had low knowledge of HIV ${ }^{31,32}$ and reported less condom negotiation skills and condom use and more anal sex than their older counterparts. ${ }^{19,21}$

HIV and syphilis were associated with low education level. Similar to findings from other studies, lower-class FSWs with a low level of education and poor knowledge of HIV/AIDS are a potential risk of HIV infection. ${ }^{14,20}$ Many of them have limited education, making them extremely vulnerable to unsafe sex and drug involvement. Moreover, HIV and syphilis were highest among separated (widow/divorced) FSWs. In the context of commercial sex, women who were divorced or widowed and low education status may have had more financial pressure and in need for livelihood as well as to support their family, which further may make them likely to have unprotected sex for more money. Women who grew up in resource-poor settings usually lacked opportunities of education and skill trainings. Without job-related skills, these women may lack opportunities to find alternative jobs and engage in sex work for livelihood and to support their

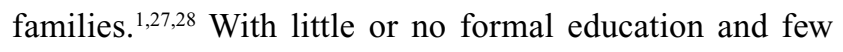
alternative employment opportunities, they tend to continue sex work for longer duration. ${ }^{28}$ Family responsibility, in combination with economic deprivation, lack of alternative options, or jobs propel women into sex work and engaging in higher risk behaviors.

HIV and syphilis were higher among street-based FSWs compared with establishment-based FSWs. The street-based FSWs had lower education levels, charged less for their services, and had engaged in commercial sex for a longer period of time than establishment-based FSWs. Consequently, the vulnerability of street-based FSWs to HIV/STIs is much higher than the establishment-based FSWs. Street-based FSWs are also more likely to inject drugs, lack of consistent condom use, and have sex with clients who are drug users or transport workers; $;^{4,5,15,19,20}$ hence, these groups are mobile and work on the highways.

Unprotected sexual behavior was also of great risk in this study. Risk significantly increased for sex with different kinds of sex partners without using condom. Duration of sex work is strongly associated with HIV and syphilis prevalence. Higher HIV and syphilis prevalence was found among FSWs working $>3$ years. The longer the FSWs are exposed to sex work, the more they are exposed to large numbers of sexual partners, high concurrency of these partners, less condom use, and inconsistent condom use. In addition to this, they are also more likely to engage in harmful alcohol use, substance abuse, or contracting HIV infection when in contact with a large number of sexual partners.

Syphilis was higher among FSWs who had inconsistent condom use with their clients and regular partners; however, in multivariate analysis, no statistical association was found. Several studies have identified that FSWs are at risk of HIV/ STIs during forced sex due to condom nonusage, condom failure, and condom refusal by clients, ${ }^{29,33,34}$ putting FSWs at direct risk of HIV/STIs during forced sex due to condom nonuse, condom failure, and increased substance use. The study found that syphilis was higher among FSWs with no clients, for example, higher among FSW $<1$ client per day and past week. It is likely that many infected FSWs know that they are infected or suspect it, and therefore, limit the number of sexual partners.

Our results suggest that sharing injecting drugs increase HIV infection among the FSW population in Nepal. HIV prevalence was higher among drug injectors. The combination of drug use and sex work in this population of FSWs make them at very high risk and an important source of infection to others. ${ }^{1,20}$ These FSWs who inject drugs should be a major focus of intervention efforts. However, having an overlapping risk of sex work and injecting drug users, they face even greater stigmatization, which isolates them from the rest of society and even from their sex-working peers. Low social status, feelings 
of inferiority, and stigmatization make this group of FSWs often less concerned about their potential infection risks (eg, low condom use with regular clients and private partners and sharing of injecting equipment) and harder to reach with intervention messages. Moreover, this strongly suggests that if left uncontrolled, the HIV epidemic could expand in this population and that this population could continue to be a source of HIV infection through its networks of sexual behavioral practices.

Syphilis was significantly associated with HIV. Epidemiologic studies demonstrate that STIs including syphilis is associated with an increased risk of HIV acquisition. ${ }^{35} \mathrm{HIV}$ and syphilis-positive FSWs are still working in the community. Our study indicates that many do not know their infection status, engage in high-risk behaviors and practices, and perceive themselves to be at low risk of HIV infection. They are likely to be spreading the virus to their clients and sexual and injecting partners. Targeted HIV prevention and treatment programs should be urgently developed and implemented for this population. Provision of condom distribution is needed for the prevention of HIV transmission through injecting network.

\section{Conclusion}

HIV prevalence had remained stable over years, whereas syphilis prevalence was significantly decreased from 2004 to 2012 with a slight increase in 2015. Data from the upcoming rounds in conjunction with IBBS round are expected to generate more specific insights on the levels of impact of intervention in the study sites. It was found that the factors, such as year, Terai region, advanced age, lower education, street-based FSWs, and longer duration of sex work, affect syphilis among FSWs. Similarly, lower education, advance age, injecting behaviors, and syphilis were associated with HIV. This study also guides policymakers design HIV and STI intervention programs based on risk factors.

\section{Limitations}

The study had few limitations. IBBS surveys are crosssectional in design and cannot provide evidence of a causal relationship between determinants and HIV. This study was conducted in three regions of Nepal, so the findings will confine to these districts, and may not be generalized to other districts or any other parts of the country. Moreover, this study review into HIV prevalence and risk behaviors only, whereas other issues related to structural risk factors (HIV and STI prevention and treatment services) have not been analyzed in detail. Moreover, there may be possibilities that same FSWs can participate in multiple rounds of surveillance survey because a survey conducted in the same area among the same group over time, so it can violate the regression assumption of independence. Despite such limitations, the positive association between background characteristics, drug injecting practices, and sexual behaviors that increase the risk of HIV and STI infection has important implications.

\section{Acknowledgments}

We express our gratitude to the National Centre for AIDS and STD Control (NCASC), Teku, Kathmandu, and Nepal, for permission to use their data. We are indebted to Prof Don $\mathrm{McNeil}$ for supervising this research. This research was also supported by the Postdoctoral Fellowship from Prince of Songkla University.

\section{Author contributions}

SK contributed to conception and design, data analysis, and manuscript preparation. All authors contributed toward data analysis, drafting, and critically revising the paper and agreed to be accountable for all aspects of the work.

\section{Disclosure}

The authors report no conflicts of interest in this work.

\section{References}

1. Baral S, Beyrer C, Muessig K, et al. Burden of HIV among female sex workers in low-income and middle-income countries: a systematic review and meta-analysis. Lancet Infect Dis. 2012;12(7):538-549.

2. Morris M, Podhisita C, Wawer MJ, Handcock MS. Bridge populations in the spread of HIV/AIDS in Thailand. AIDS. 1996;10(11):1265-1271.

3. National Center for AIDS and STD Control. Mapping and size estimation of most at risk population in Nepal. Kathmandu, Nepal; 2011.

4. National Center for AIDS and STD Control. Integrated Biological and Behavioral Surveillance (IBBS) Survey among Female Sex Workers in Kathmandu Valley, Nepal, Round V. Kathmandu, Nepal; 2015.

5. National Center for AIDS and STD Control. Integrated Biological and Behavioral Surveillance (IBBS) Survey among Female Sex Workers in Pokhara Valley, Round V. Kathmandu, Nepal; 2015.

6. Morrison L, Weiss H, Buve A, et al; Study Group on Heterogeneity of HIV Epidemics in African Cities. Commercial sex and the spread of HIV in four cities in sub-Saharan Africa. AIDS. 2001;15(Suppl 4):S61-S69.

7. National Center for AIDS and STD Control. National Estimates of HIV Infections in Nepal 2014. Kathmandu, Nepal; 2014.

8. Watts C, Zimmerman C, Foss AM, Hossain M, Cox A, Vickerman P Remodelling core group theory: the role of sustaining populations in HIV transmission. Sex Transm Infect. 2010;86(Suppl 3):iii85-iii92.

9. Kilmarx PH. Global epidemiology of HIV. Curr Opin HIV AIDS. 2009; 4(4):240-246.

10. Cwikel JG, Lazer T, Press F, Lazer S. Sexually transmissible infections among female sex workers: an international review with an emphasis on hard-to-access populations. Sex Health. 2008;5(1):9-16.

11. Cohen MS. Sexually transmitted diseases enhance HIV transmission: no longer a hypothesis. Lancet. 1998;351(Suppl 3):5-7.

12. Medhi GK, Mahanta J, Paranjape RS, Adhikary R, Laskar N, Ngully P. Factors associated with HIV among female sex workers in a high HIV prevalent state of India. AIDS Care. 2012;24(3):369-376.

13. Strathdee SA, Philbin MM, Semple SJ, et al. Correlates of injection drug use among female sex workers in two Mexico-U.S. border cities. Drug Alcohol Depend. 2008;92(1-3):132-140. 
14. Tuan NA, Fylkesnes K, Thang BD, et al. Human immunodeficiency virus (HIV) infection patterns and risk behaviours in different population groups and provinces in Vietnam. Bull World Health Organ. 2007;85(1):35-41.

15. National Center for AIDS and STD Control. Integrated Biological and Behavioral Surveillance Survey (IBBS) among Female Sex Workers in 22 Terai Highway Districts of Nepal, Round IV. Kathmandu, Nepal; 2009.

16. Tongkumchum $\mathrm{P}, \mathrm{McNeil} \mathrm{D}$. Confidence intervals using contrasts for regression model. Songklanakarin J Sci Technol. 2009;31(2):151-156.

17. Chutinantakul A, Tongkumchum P, Bundhamcharoen K, Chongsuvivatwong V. Correcting and estimating HIV mortality in Thailand based on 2005 verbal autopsy data focusing on demographic factors, 1996-2009. Popul Health Metr. 2014;25:1-8.

18. Kongchouy N, Sampantarak U. Confidence interval for adjusted proportions using logistic regression. Mod Appl Sci. 2010;4(6):1-7.

19. Nemoto T, Iwamoto M, Colby D, et al. HIV-related risk behaviors among female sex workers in Ho Chi Minh City, Vietnam. AIDS Educ Prev. 2008;20(5):435-453.

20. Tran TN, Detels R, Long HT, Van Phung L, Lan HP. HIV infection and risk characteristics among female sex workers in Hanoi, Vietnam. J Acquir Immune Defic Syndr. 2005;39(5):581-586.

21. Semple SJ, Stockman JK, Pitpitan EV, et al. Prevalence and correlates of client-perpetrated violence against female sex workers in 13 Mexican Cities. PLoS One. 2015;10(11):e0143317.

22. Conners EE, Silverman JG, Ulibarri M, et al. Structural determinants of client perpetrated violence among female sex workers in two MexicoU.S. Border Cities. AIDS Behav. 2016;20(1):215-224.

23. Ghys PD, Diallo MO, Ettiegne-Traoré V, et al. Increase in condom use and decline in HIV and sexually transmitted diseases among female sex workers in Abidjan, Côte d'Ivoire, 1991-1998. AIDS. 2002;16(2):251-258.

24. Damacena GN, Szwarcwald CL, de Souza PR, Dourado I. Risk factors associated with HIV prevalence among female sex workers in 10 Brazilian Cities. J Acquir Immune Defic Syndr. 2011;57(Suppl 3): S144-S152.
25. Shen Z, Zhang C, Xiaoming, Li, et al. HIV-related behavioral risk factors among older female sex workers in Guangxi China. AIDS Care. 2014;26(11):1407-1410.

26. Zhou Y, Li X, Zhang C, et al. Rates of HIV, syphilis, and HCV infections among different demographic groups of female sex workers in Guangxi China: evidence from 2010 national sentinel surveillance data. AIDS Care. 2013;25(11):1433-1441.

27. Zhang C, Li X, Hong Y, Zhou Y, Liu W, Stanton B. Unprotected sex with their clients among low-paying female sex workers in southwest China. AIDS Care. 2013;25(4):503-506.

28. Hao C, Liu H, Sherman SG, et al. Typology of older female sex workers and sexual risk for HIV infection in China: a qualitative study. Cult Health Sex. 2014;16(1):47-60.

29. Decker MR, McCauley HL, Phuengsamran D, Janyam S, Silverman JG. Sex trafficking, sexual risk, sexually transmitted infection and reproductive health among female sex workers in Thailand. J Epidemiol Community Health. 2011;65(4):334-339.

30. Urada LA, Malow RM, Santos NC, Morisky DE. Age differences among female sex workers in the Philippines: sexual risk negotiations and perceived manager advice. AIDS Res Treat. 2012;2012:812635.

31. Sarkar K, Bal B, Mukherjee R, et al. Sex-trafficking, violence, negotiating skill, and HIV infection in brothel-based sex workers of eastern India, adjoining Nepal, Bhutan, and Bangladesh. J Health Popul Nutr. 2008;26(2):223-231.

32. Silverman JG, Decker MR, Gupta J, Maheshwari A, Wills BM, Raj A. HIV prevalence and predictors of infection in sex-trafficked Nepalese girls and women. JAMA. 2007;298(5):536-542.

33. Ramesh S, Ganju D, Mahapatra B, Mishra RM, Saggurti N. Relationship between mobility, violence and HIV/STI among female sex workers in Andhra Pradesh, India. BMC Public Health. 2012;12:764.

34. Sherwood JA, Grosso A, Decker MR, et al. Sexual violence against female sex workers in The Gambia: a cross-sectional examination of the associations between victimization and reproductive, sexual and mental health. BMC Public Health. 2015;15:270.

35. Zetola NM, Klausner JD. Syphilis and HIV infection: an update. Clin Infect Dis. 2007;44(9):1222-1228.
HIV/AIDS - Research and Palliative Care

\section{Publish your work in this journal}

HIV/AIDS - Research and Palliative Care is an international, peerreviewed open access journal focusing on advances in research in HIV, its clinical progression and management options including antiviral treatment, palliative care and public healthcare policies to control viral spread. The journal is included in PubMed. The manuscript man-

\section{Dovepress}

agement system is completely online and includes a very quick and fair peer-review system, which is all easy to use. Visit http://www.dovepress com/testimonials.php to read real quotes from published authors. 